\title{
Vacinas e movimentos antivacinação: origens e consequências
}

\author{
Vaccines and anti-vaccination movements: origins and consequences
}

Vacunas y movimientos contra la vacunación: orígenes y consecuencias

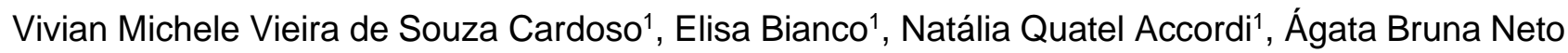
Maia Pimentel ${ }^{1 *}$, Fabyolla da Silva Lourenço ${ }^{1}$, Valéria Dulce Cressoni ${ }^{2}$, Ana Cristina Felício Rios Miranda $^{2}$, Clarice Santana Milagres ${ }^{1,2}$.

\section{RESUMO}

Objetivo: Apresentar um histórico sobre as vacinas, contextos, receios e consequências de não as utilizar e, origens e consequências advindas dos movimentos antivacinação. Revisão bibliográfica: As vacinas são consideradas a melhor forma de prevenção de doenças infecciosas. Contudo, apesar das conquistas obtidas pela vacinação em nível mundial, um movimento contrário à aplicação dos imunobiológicos também surgiu e ganha notoriedade, principalmente após a publicação de resultados associando a vacina da tríplice ao autismo Este movimento, conhecido como movimento antivacinação, cresce continuamente e utiliza de informações chamadas "fake news", que, impulsionadas, pela ausência de conhecimento fundamentado em estudos científicos sérios sobre os imunobiológicos e seus muitos benefícios, aumentam o potencial de retorno de diversas doenças já controladas pela vacinação. Considerações finais: É notável a importância das vacinas no controle das doenças infeciosas ao longo dos anos, assim como os avanços relacionados aos custos, efetividade, eficácia e segurança dos imunobiológicos. Entretanto, movimentos antivacinação crescem continuamente e trazem consigo riscos ao retorno de doenças já controladas.

Palavras-chave: Imunização, Movimentos antivacinação, Vacina.

\begin{abstract}
Objective: To present a history of vaccines, contexts, fears and consequences of not using them, origins and consequences of anti-vaccination movements. Bibliographic review: Vaccines are considered the best way to prevent infectious diseases. However, despite the achievements obtained by vaccination worldwide, a movement against the application of immunobiologicals has also emerged and gained notoriety, especially after the publication of results associating the triple vaccine with autism. This movement, known as the antivaccination movement, grows continuously and uses of information called "fake news", which, driven by the lack of knowledge based on serious scientific studies on immunobiologicals and their many benefits, increase the potential for return of several diseases already controlled by vaccination. Final considerations: The importance of vaccines in the control of infectious diseases over the years is remarkable, as well as the advances related to the costs, effectiveness, efficacy and safety of immunobiologicals. However, antivaccination movements are continually growing and bring risks to the return of diseases that have already been controlled.
\end{abstract}

Key words: Immunization, Anti-vaccination movements, Vaccine.

\section{RESUMEN}

Objetivo: Presentar una historia de vacunas, contextos, miedos y consecuencias de no usarlos y, orígenes y consecuencias de los movimientos anti-vacunación. Revisión bibliográfica: Las vacunas se consideran la mejor forma de prevenir enfermedades infecciosas. Sin embargo, a pesar de los logros obtenidos por la vacunación a nivel mundial, también ha surgido y ganado notoriedad un movimiento contra la aplicación de inmunobiológicos, especialmente tras la publicación de resultados que asocian la triple vacuna con el autismo.

${ }^{1}$ Centro Universitário da Fundação Hermínio Ometto (FHO), Araras - SP. "E-mail: agatabmaia@outlook.com

2 Faculdade São Leopoldo Mandic, Araras - SP. 
Este movimiento, conocido como movimiento antivacunación, crece continuamente y utiliza de información denominada "fake news", que, impulsada por el desconocimiento basado en estudios científicos serios sobre inmunobiológicos y sus múltiples beneficios, aumenta la posibilidad de reaparición de varias enfermedades ya controladas por la vacunación. Consideraciones finales: Es notable la importancia de las vacunas en el control de enfermedades infecciosas a lo largo de los años, así como los avances relacionados con los costos, efectividad, eficacia y seguridad de los inmunobiológicos. Sin embargo, los movimientos contra la vacunación están en continuo crecimiento y conllevan riesgos para el regreso de enfermedades que ya han sido controladas.

Palabras clave: Inmunización, Movimientos anti-acunación, Vacuna.

\section{INTRODUÇÃO}

O sistema imunológico humano armazena anticorpos produzidos através dos linfócitos $B$, e estes, estimulados pela aplicação de vacinas, que apresentam o potencial de incitar a criação de anticorpos, conferindo memória imunológica ao indivíduo, que ao entrar em contato com microrganismos e, já possuindo os devidos anticorpos sistemicamente circulantes, agirão para eliminá-los, evitando assim a disseminação de diversas doenças (BRASIL, 2014; BRALALAI I, 2017).

Nos últimos dois séculos ficou evidente e notável a luta contra doenças infectocontagiosas e, neste contexto as vacinas contribuíram para seu controle, impactando na redução da morbidade infantil e dos custos advindos destas doenças. A crescente efetividade, eficácia e segurança dos imunobiológicos criados, tornou a vacinação obrigatória nos programas de saúde pública, contribuindo, portanto, com o aumento da cobertura homogênea e com equidade (SUCCI RCM, 2018).

Apesar destas conquistas, um movimento contrário à aplicação dos imunobiológicos também surgiu. A antivacinação ganhou notoriedade e força após um renomado pesquisador e cirurgião, Andrew Wakefield, publicar no periódico de alto impacto (The Lancet) em 1998 um trabalho sugerindo que o imunobiológico tríplice viral estivesse diretamente ligado ao aparecimento de autismo nas crianças que haviam feito uso dessa vacina (WAKEFIELD AJ, et al., 1998; STEVANIM LF, 2018). Infelizmente, e após a retratação pela Revista, este trabalho ainda apresenta consequências de seus resultados equivocados, se mantendo atualmente (RETRACTION, 2010).

Os movimentos antivacinas crescem continuamente no mundo trazendo consigo consequências como o ressurgimento de doenças imunopreveníveis. A deficiência nas informações propagadas tem contribuído para a reemergência das doenças infecciosas e colocando em risco planos mundiais para erradicação de muitas dessas enfermidades. Tais movimentos distorcem e divulgam Fake News, alegam bases científicas para questionar eficiência, eficácia e segurança das vacinas, além da sua forma de produção. Vale acrescentar que locais com maior acesso às mídias sociais possuem crescente incidência de indivíduos contrários à vacinação devido ao acesso facilitado às informações falsas (SATO APS, 2018).

Logo, uma das mais importantes consequências destes movimentos é a redução das coberturas vacinais, especialmente em crianças menores de cinco anos; e a hesitação vacinal, caracterizada pelo atraso na aceitação ou recusa de vacinação a despeito da disponibilidade de vacinas (ZORZETTO R, 2018; SATO APS, 2018). A definição de recusa vacinal não é, portanto, um processo entre aceitação e recusa do uso de imunobiológicos, mas um "continuum" entre estas duas situações (OMS, 2015).

A queda das coberturas vacinais infantis e suas consequências já são visíveis e, infelizmente, crescentes, assim como a hesitação vacinal, que também tem se tornado cada vez mais evidente e preocupante. Dessa forma, o objetivo deste trabalho é apresentar um histórico sobre as vacinas, contextos, receios e consequências de não as utilizar e, origens e consequências advindas do movimento antivacinação.

\section{REVISÃO BIBLIOGRÁFICA}

Esta revisão de literatura apresentou uma abordagem qualitativa, com abordagem sobre as vacinas e o movimento antivacinação, com suas origens e consequências. Foram analisados trabalhos em português e 
inglês, inseridos nas bases bibliográficas de dados internacionais PubMed e Science Direct, com os descritores "immunization programs" "anti-vaccination movements" e vaccine. As demais bases de dados utilizadas foram a BVS, Scielo e LILACS, que utilizaram os descritores imunização, "movimentos antivacinação" e vacina.

A data de publicação dos artigos utilizados priorizou os dez últimos anos. Contudo, para fidelizar a contextualização histórica, também se recorreu a outras literaturas para inclusão de informações relativas às linhas orientadoras que dizem respeito ao histórico de vacinação e ao panorama de imunização brasileiro. Esta última, orientada pelo Ministério da Saúde e Programa Nacional de Imunização através das legislações, Resoluções e Normas Técnicas para maior fidelização da revisão proposta.

Os estudos encontrados e analisados em sua grande maioria foram quantiqualitativos e revisões integrativas de literatura, que apresentaram resultados originais e copilados de informações, respectivamente. Para melhor entendimento, a revisão foi dividida em duas abordagens: "Vacinas: históricos, contextos, receios e consequências de não as utilizar" e "Movimento Antivacina: origens e consequências".

\section{Vacinas: históricos, contextos, receios e consequências de não as utilizar}

Vacinas são composições direcionadas para algumas doenças introduzidas no organismo que ativam a formação de anticorpos, fazendo com que em contato com esses patógenos possa ser combatido. Elas são feitas de microrganismos inativados ou atenuados, além de serem consideradas a melhor forma de prevenção de doenças infecciosas, haja vista que o controle de tais doenças apresenta custos significativos, que requerem medicações específicas e atenção à saúde em níveis secundários e terciários. A vacina apresenta o melhor custo-benefício, são apontadas como seguras, eficazes e importantes na prevenção de doenças (CRUZ F, 2019).

Louis Pasteur, em 1885 (quase um século após a descoberta do primeiro imunobiológico que faria prevenção à varíola) desenvolveu uma nova forma de utilizar um organismo (vírus) para provocar a formação de anticorpos, desenvolvendo, portanto, a imunidade ativa. O pesquisador utilizou a medula espinhal seca de coelhos e cães infectados com o vírus para o desenvolvimento da vacina contra a raiva (LEVI GC, 2013; SATO APS, 2018). Vale ressaltar que até esta descoberta o nome "vacina" não havia sido mencionado na literatura científica e foi definida como uma homenagem à Jenner, o descobridor do cowpox bovino (HOMMA A, et al., 2010).

Edward Jenner, no século XVIII, em um experimento, extraiu o líquido da ferida que continha o vírus causador da varíola nas vacas, inserindo-o em arranhões realizados por ele em um braço de um garoto, comprovando posteriormente, a imunidade deste garoto ao vírus da varíola. Diante deste fato, foi iniciada a criação de vacinas para prevenção não somente da varíola, mas de outras doenças (LEVI GC, 2013).

A progressão da ciência sobre os imunobiológicos ganhou força e, em 1980, após diversas descobertas, disseminação e utilização das vacinas, contestou-se sobre aquela que previne a coqueluche devido à utilização de células inteiras. Tal descoberta impulsionou a pesquisa e produção da vacina com produção acelular, conferindo a mesma eficácia que a primeira já utilizada (SATO APS, 2018).

Com relação às vacinas, existiram e ainda persistem alguns receios na população. Em especial, estes receios relacionam-se aos métodos de produção dos imunobiológicos e suas composições. No mais, o uso de animais em testes vacinais gerou controvérsias entre a população, com temores que variavam desde a própria vacina, quanto à utilização dos animais nos testes e até mesmo, contrair a patologia de forma mais grave. Tais motivos dificultaram a disseminação da vacinação e causaram revoltas (ZORZETTO R, 2018).

Como um importante marco na saúde pública, a utilização de animais em pesquisas cientificas, auxiliou no controle de qualidade de vacinas contra poliomielite, tétano, sarampo, difteria, hepatite, meningite e a febre amarela e após décadas de pesquisa, produção, manipulação e distribuição das vacinas, a utilização de animais em laboratórios está sendo submetido a um movimento internacional baseado nos 3Rs: substituir ("Replacement'), reduzir ("Reduction") e refinar (“Refinement") (BROCKINGTON G e MESQUITA L, 2016). Estes, visam principalmente a substituição de animais vivos por materiais insensíveis, apresentando, portanto, 
redução no número de animais utilizados para obtenção de quantidade e precisão; e evitando procedimentos desnecessários realizados em animais nos laboratórios (SUCCI RCM, 2018; MIZUTA AH, et al., 2019).

Nos Estados Unidos, como maneira de controle, foi estabelecido um sistema de vigilância passivo de Eventos Adversos Pós-Vacinação (EAPV), visando fornecer transparência e auxílio à população. A partir de 1990 houve publicações de artigos associando a vacina tríplice viral (SCR: Sarampo, Caxumba e Rubéola) à doença de Crohn e posteriormente ao autismo (SATO APS, 2018). Esta perspectiva de receio populacional, em âmbito mundial, aumentou e modificou as formas de compartilhamento de informações, erroneamente colocadas, e assim denominadas Fake News ou notícias falsas. Atualmente, diversos motivos ainda são utilizados para justificar o movimento contrário à utilização de vacinas, em especial pelo desconhecimento das formas de produção e eventos adversos possíveis. Diante das mais equivocadas e diferentes informações transmitidas sobre os imunobiológicos, ainda nos Estados Unidos, em 1920, com a vacinação obrigatória, constantes brigas judiciais foram travadas contra tal obrigatoriedade (MICHELIN L, 2019).

Em contrapartida, em países de renda mais alta, entre 1950 e 1960, a "Era de Ouro" da aceitação vacinal foi estabelecida com a introdução da vacina tríplice viral e contra a poliomielite, no qual foram observadas quedas expressivas e visíveis nas manifestações dessas doenças (SATO APS, 2018). Quanto aos países com média e baixa renda, foi disponibilizado o auxílio de iniciativas globais, contribuindo para o desenvolvimento de programas de imunização. Em 1987, a Organização Mundial da Saúde (OMS) estabeleceu o Programa Ampliado de Imunização (PAI), com objetivo principal de promover a vacinação mundial, sendo responsável pelo aumento da cobertura vacinal da tríplice bacteriana (DTP: difteria, tétano e coqueluche) e por manter a erradicação da varíola (SATO APS, 2018). A construção da linha do tempo da criação dos imunobiológicos pode ser observada na Figura 1.

Em 2000, com o objetivo de trazer equidade e possibilitar o acesso às novas vacinas desenvolvidas, 0 Global Alliance For Vaccines And Immunisation foi desenvolvido nos países de baixa renda (HOMMA A, et al., 2010; SATO APS, 2018), enquanto no Brasil foi criado o Programa Nacional de Imunização (PNI), promovendo a vacinação gratuita para os brasileiros com mais de 15 antígenos e soros diferentes. O PNI aprimorado continuamente, torna-se mais complexo e oferta uma maior quantidade de vacinas, além de implementar necessárias mudanças em esquemas vacinais que ocorrem diante das transições epidemiológicas e demográficas instaladas em nosso país (BRASIL, 2014; SATO APS, 2018).

Figura 1 - Linha do tempo de vacinas.

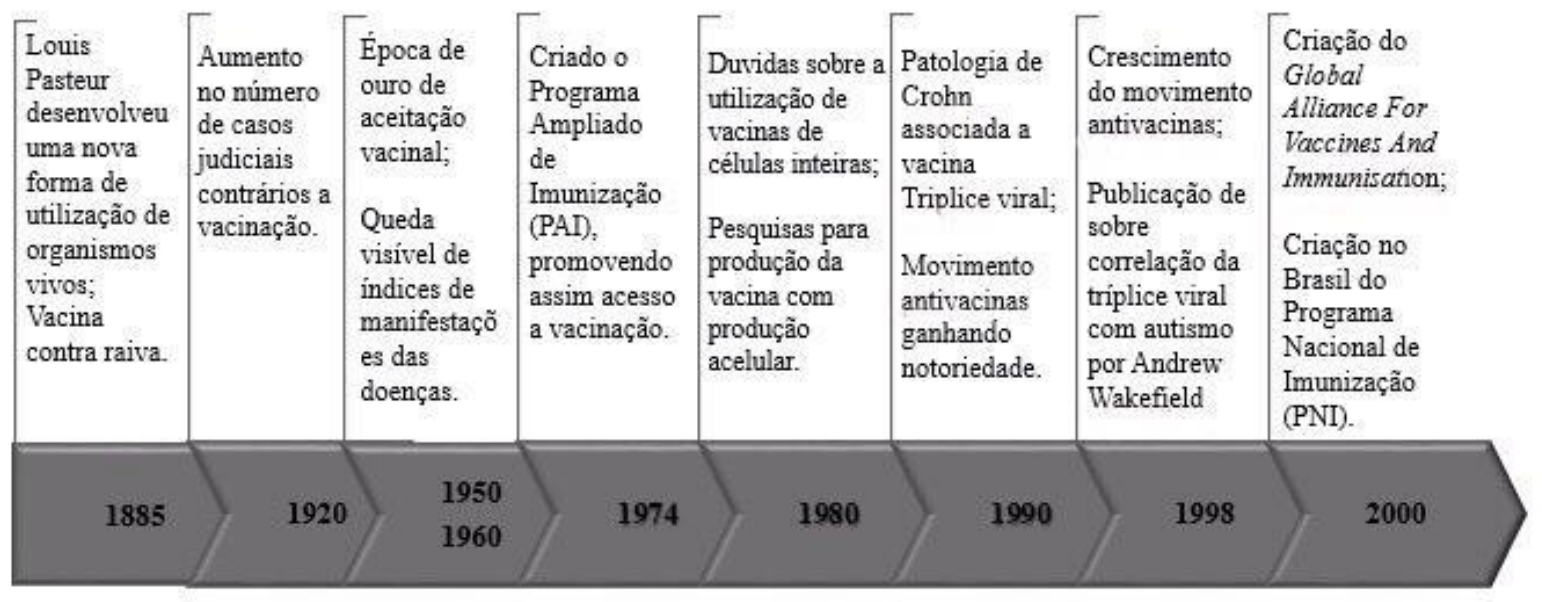

Fonte: CARDOSO VMVS, et al., 2021.

\section{Movimento Antivacina: origens e consequências}

Mesmo com diversos estudos que apresentam alto impacto científico e populacional para a saúde pública no mundo, apontando as vantagens da vacinação, ainda há movimentos antivacinação em ascensão. Estes movimentos utilizam questionamentos infundados sobre eficiência, eficácia, produção e até mesmo potenciais 
doenças causadas pelo uso das vacinas, assim como a real necessidade de vacinação. Estes movimentos ganham espaço e notoriedade na disseminação mundial de informações equivocadas. Chamadas de Fake News, tais informações se espalham pelas mídias sociais e trazem abordagens negativas sobre as vacinas. Estão respaldadas por amplas formas de propagação de informações, como erros científicos, crenças religiosas (a doença só ocorre com a permissão de Deus e ao receber a imunização o indivíduo estaria impedindo a sua ocorrência e saindo do domínio de Deus, e, portanto, cometendo um pecado), filosóficas, desconhecimentos sobre imunologia (a imunidade adquirida através da doença é maior do que adquirida pela vacina), medo das reações dos imunobiológicos, dentre outros. A maioria dessas informações e o crescente número de seguidores dos grupos antivacinas, disseminam estas e outras Fake News, impulsionadas, pela ausência de conhecimento real e científico sobre os imunobiológicos e seus muitos benefícios (LEVI GC, 2013; SUCCI RCM, 2018; MIZUTA AH, et al., 2019).

$\mathrm{O}$ apoio de algumas classes médicas junto aos movimentos antivacionais também podem ser vistos. Pediatras contrários a vacinação associam aplicações excessivas de vacinas nos primeiros anos de vida (em especial até o primeiro ano de vida da criança) às doenças já erradicadas. Logo, não haveria necessidade de aplicação de muitas vacinas e, consequentemente, redução dos eventos adversos que podem ser observados como febre alta e convulsões. Atitudes como estas reforçam a desinformação sobre os imunobiológicos, sua importância individual e coletiva (MICHELIN L, 2019).

A exemplo de como as informações publicadas de forma parcial e incorreta podem ser disseminadas, a notoriedade e força do movimento antivacina ganhou espaço após o médico cirurgião Andrew Wakefield publicar, em 1998, na Lancet (revista de alto impacto em meio à sociedade cientifica), um trabalho associando a utilização da vacina tríplice viral ao desenvolvimento do autismo nas crianças pesquisadas (BROCKINGTON G e MESQUITA L, 2016).

Nesta publicação, Wakefield realizou uma pesquisa na qual foram incluídas 12 crianças inglesas, nas idades entre três e dez anos, encaminhadas a uma unidade pediátrica hospitalar do Royal Free Hospital. As crianças selecionadas apresentavam casos clínicos similares com presenças de dor abdominal e diarreia, além de mudanças no comportamento. Nove das crianças envolvidas no estudo foram posteriormente diagnosticadas com autismo e colite sem especificação. Estes resultados deflagraram a grande força que 0 movimento antivacina necessitou para alavancar informações repassadas aos pais de crianças que são vacinadas e o risco da vacina dessa vacina específica. Ressalta-se que neste estudo, Wakefield relata que as crianças teriam sido vacinadas com a tríplice viral, havendo, portanto, associação com as patologias encontradas, especialmente ao autismo (CARNEIRO AV, et al., 2011; VASCONCELLOS-SILVA PR, et al., 2015; CARVALHO IVRL, et al., 2015; BARBOZA R e MARTORANO SAA, 2017; MICHELIN L, 2019). Estes dados foram utilizados pelo autor para advogar contra o uso deste imunobiológico e a favor de vacinações individuais com conflito de interesse pessoal (BARBOZA R e MARTORANO SAA, 2017).

Para explicar a associação do autismo pelo uso da tríplice viral, o estudo intitulado "Ileal-lymphoid-nodular hyperplasia, nonspecific colitis, and pervasive developmental disorder in children" (traduzido para o português como "Hiperplasia linfóide-nodular ileal, colite inespecífica e transtorno invasivo do desenvolvimento em crianças") os autores alegaram que os componentes da vacina ocasionavam inflamação intestinal e com comprovação. A hipótese criada foi de que este imunobiológico diminuiria o sistema imunológico, levando à translocação de alguns peptídeos na corrente sanguínea. Estes, por sua vez, chegavam ao cérebro das crianças, previamente vacinadas, manifestando a doença. Com a publicação destes resultados na Lancet e divulgados mundialmente, muitos pais e responsáveis se recusaram a vacinar suas crianças. Na Inglaterra, país onde foi conduzido este estudo, após esta publicação, apresentaram redução das taxas de cobertura vacinal (94\% para $75 \%$ ) e foram seguidas mundialmente (BROCKINGTON G e MESQUITA L, 2016; BARBOZA R e MARTORANO SAA, 2017; VASCONCELLOS-SILVA PR, et al., 2015).

As afirmações pelo renomado pesquisador foram questionadas mediante a metodologia empregada, como a fundamentação teórica-científica da associação direta entre a vacinação e a patologia encontrada, reduzida amostra da pesquisa e sem apresentação do grupo controle, ausência das reais possibilidades e probabilidades de vacinação e autismo, ausência de padrão para diagnosticar as crianças pesquisadas e, 
finalmente, a realização da endoscopia, feita de maneira incorreta e invasiva, trouxe resultados inconclusivos (BROCKINGTON G e MESQUITA L, 2016; BARBOZA R e MARTORANO SAA, 2017).

Exaustivamente questionado, em especial pelos métodos invasivos realizados desnecessariamente em crianças sob seus cuidados e investigação, Wakefield teve seu registro profissional cassado pelo General Medical Council (GMC - Conselho Federal de Medicina Inglês) (BARBOZA R e MARTORANO SAA, 2017), que mostraram, após investigação, que os dados da pesquisa foram forjados. Alguns autores apresentavam conflitos de interesse, havia associação junto à advogados que visavam indenizações alegando patologias adquiridas pela utilização de vacinas, e, por fim, o registro de patente de um imunobiológico anti-sarampo com alegação de maior segurança (VASCONCELLOS-SILVA PR e CASTIEL LD, 2010).

Após todas essas conclusões das investigações, a revista retirou o artigo de seus arquivos, retratando-se após doze anos com a assinatura de dez dos treze autores envolvidos. Dentre aqueles que não assinaram, estava o principal pesquisador, Andrew Wakefield (RETRACTION, 2010; BARBOZA R e MARTORANO SAA, 2017; PARK M, 2010).

Todas as avaliações, investigações e estudos realizados concluíram que a vacinação e o autismo não apresentavam qualquer relação, contudo não excluíram totalmente essa possibilidade, mantendo pais apreensivos. Mesmo com as conclusões da investigação, retratação pela maioria dos autores e estudos com alta qualidade metodológica, seguiu, até a devida retratação, uma redução da cobertura e número de crianças vacinadas, além do reaparecimento de casos de sarampo na América do Norte e Europa (BROCKINGTON G e MESQUITA L, 2016; PETRAGLIA TCMB, et al., 2020).

Infelizmente, os grupos defensores do movimento antivacina e que ainda associam a vacina tríplice viral ao desenvolvimento de autismo, desconsideram os demais estudos conduzidos que evidenciaram resultados contrários. Vale ressaltar que estes defensores ignoram informações que comprovem que pessoas não vacinadas podem e contraem sarampo, havendo maior possibilidade de sofrerem danos neurológicos, auditivos e até mesmo ir a óbito (BROCKINGTON G e MESQUITA L, 2016).

Mundialmente, o trabalho de Wakefield apresentou um impacto expressivo. Nos Estados Unidos houve (e ainda há) um grande e forte movimento antivacina. Em 2004 foram reportados 37 casos de sarampo em todos os Estados. Em 2014 o número alcançou 644 confirmações e em janeiro de 2015, foram diagnosticados 59 indivíduos com sarampo na Califórnia. Sobre este último dado, foi constatado por um surto iniciado na Disneylândia que migrou para todo o Estado. A medida protetiva instaurada pela justiça foi a proibição de estudantes nas escolas caso não houvessem sido vacinados (BROCKINGTON G e MESQUITA L, 2016). Já em países como Japão e Polônia, onde a vacinação da tríplice viral foi temporariamente suspensa, foi observado um menor risco de autismo entre crianças que haviam sido vacinadas, corroborando mais uma vez com a associação da manifestação do autismo pela vacina (VASCONCELLOS-SILVA PR e CASTIEL LD, 2010).

Nas Américas, o retorno do sarampo ocorreu, principalmente, pela baixa cobertura vacinal, consequência do crescente número de Fake News e resultados equivocados associando a vacina tríplice viral ao autismo (STEVANIM LF, 2018). No Brasil, um surto de sarampo em 2018 evidenciou as baixas coberturas vacinais. Em 2019, no país, foram confirmados 2109 casos da doença, sendo 98\% provenientes do Estado de São Paulo (PETRAGLIA TCMB, et al., 2020). Estas reduzidas coberturas trazem consigo ainda o receio da volta de outras doenças, como a poliomielite e a coqueluche, já que também tem apresentado reduzidas coberturas (LESSA SC e SCHRAMM FR, 2015; ZORZETTO R, 2018; PETRAGLIA TCMB, et al., 2020).

\section{CONSIDERAÇÕES FINAIS}

É notável a importância das vacinas no controle das doenças infeciosas ao longo dos anos, assim como os avanços relacionados aos custos, efetividade, eficácia e segurança dos imunobiológicos. Contudo, apesar das conquistas obtidas pela vacinação em nível mundial, um movimento contrário à aplicação de vacinas também surgiu e ganha notoriedade. É conhecido como movimento antivacinação, que cresce continuamente e utiliza de informações chamadas Fake News que, impulsionadas pelo desconhecimento sobre 
imunobiológicos e seus muitos benefícios, aumentam o potencial de retorno de doenças já controladas pela vacinação, trazendo consigo risco aos planos mundiais para a erradicação das daquelas que são imunopreviníveis.

\section{REFERÊNCIAS}

1. BARBOZA R, MARTORANO SAA. O caso da vacina tríplice e o autismo: o que os erros nos ensinam sobre os aspectos da natureza da ciência. São Bernardo do Campo: Editora UFABC, 2017; 18p.

2. BRALALAI I. Imunização: Tudo que você sempre quis saber. 3.ed. Rio de Janeiro: RMCOM, 2017; 294p.

3. BRASIL. Manual de Normas e Procedimentos para Vacinação. Brasília: Ministério da Saúde, 2014; 178p.

4. BROCKINGTON G, MESQUITA L. As consequências da má divulgação científica. Revista da Biologia, 2016; 15(1): 29-34.

5. CARNEIRO AV, et al. Efetividade clínica e análise económica da vacinação preventiva. Acta Médica Portuguesa, 2011; 24(4): 565-586.

6. CARVALHO IVRL, et al. Conhecimento das Mães a Respeito das Vacinas Administradas no Primeiro Ano de Vida. Revista Brasileira de Ciências da Saúde, 2015; 19(3): 205-210.

7. CRUZ F. 2019. In: Vacinas: perguntas frequentes sobre vacinas. Perguntas frequentes sobre vacinas. Rio de Janeiro: Fiocruz.

8. HOMMA A, et al. Atualizações em vacinas, imunizações e inovação tecnológica. Scielo Saúde Pública, 2010; 16(2): 445-458.

9. LESSA SC, SCHRAMM FR. Proteção individual versus proteção coletiva: análise bioética do programa nacional de vacinação infantil em massa. Ciência \& Saúde Coletiva, 2015; 20(1): 115-124.

10. LEVI GC. Recusa de vacinas: causas e consequências. São Paulo: Segmento Farma, 2013; 74p.

11. MICHELIN L. Boletim: Movimentos Antivacinação e o impacto na saúde da população. Paraiso: Sociedade Brasileira de Infectologia 1980, 2019; 21p.

12. MIZUTA AH, et al. Percepções acerca da importância das vacinas e da recusa vacinal numa escola de medicina. Revista Paulista de Pediatria, 2019; 37(1): 34-40.

13. OMS - WORLD HEALTH ORGANIZATION. 2015. In: Immunization coverage. Geneva: WHO.

14. PARK M. 2010. In: Medical journal retracts study linking autismo to vaccine. Atlanta: CNN

15. PETRAGLIA TCMB, et al. Falhas vacinais: avaliando vacinas febre amarela, sarampo, varicela e caxumba. Cadernos de Saúde Pública, 2020; 36(Suppl 2): 1-14.

16. RETRACTION. Ileal-lymphoid-nodular hyperplasia, non-specific colitis, and pervasive developmental disorder in children. The Lancet, 2010; 375(9713): 445.

17. SATO APS. What is the importance of vaccine hesitancy in the drop of vaccination coverage in Brazil? Revista de Saúde Pública [online], 2018; 52: 96.

18. STEVANIM LF. Sarampo de volta ao mapa. Radis, 2018 Ago; 1(191): 10-11.

19. SUCCI RCM. Vaccine refusal: what we need to know. J. Pediatr., 2018; 94(6): 574-581.

20. VASCONCELLOS-SILVA PR, CASTIEL LD. A internet na história dos movimentos anti-vacinação. ComCiência, 2010; (121): 0-0.

21. VASCONCELLOS-SILVA PR, et al. A sociedade de risco midiatizada, o movimento antivacinação e o risco do autismo. Ciência Saúde Coletiva, 2015; 20(2): 607-616.

22. WAKEFIELD AJ, et al. Retracted: Ileal-lymphoid-nodular hyperplasia, nonspecific colitis, and pervasive developmental disorder in children. The Lancet, 1998; 351(9103): 637-641.

23. ZORZETTO R. As razões da queda na vacinação: Ao menos nove fatores contribuem para a redução na imunização infantil e aumentam o risco de doenças graves ressurgirem. 270. ed. São Paulo: Revista Pesquisa Fapesp, 2018; 7p. 